\title{
BMJ Open Enablers and barriers to treatment adherence in heterozygous familial hypercholesterolaemia: a qualitative evidence synthesis
}

\author{
Fiona J Kinnear, ${ }^{\oplus 1}$ Elaine Wainwright, ${ }^{2,3}$ Rachel Perry, ${ }^{1}$ Fiona E Lithander, ${ }^{1}$ \\ Graham Bayly, ${ }^{4}$ Alyson Huntley, ${ }^{\circ}$ Jennifer Cox, ${ }^{1}$ Julian PH Shield, ${ }^{1}$ Aidan Searle ${ }^{1}$
}

To cite: Kinnear FJ, Wainwright E, Perry R, et al. Enablers and barriers to treatment adherence in heterozygous familial hypercholesterolaemia: a qualitative evidence synthesis. BMJ Open 2019;9:e030290. doi:10.1136/ bmjopen-2019-030290

- Prepublication history and additional material for this paper are available online. To view these files, please visit the journal online (http://dx.doi org/10.1136/bmjopen-2019030290).

Received 07 March 2019 Revised 19 June 2019 Accepted 02 July 2019

Check for updates

(C) Author(s) (or their employer(s)) 2019. Re-use permitted under CC BY. Published by BMJ.

For numbered affiliations see end of article.

Correspondence to

Fiona J Kinnear;

fiona.kinnear@bristol.ac.uk

\section{ABSTRACT}

Objectives Individuals with heterozygous familial hypercholesterolaemia $(\mathrm{FH})$ are at high risk of developing cardiovascular disease (CVD). This risk can be substantially reduced with lifelong pharmacological and lifestyle treatment; however, research suggests adherence is poor. We synthesised the qualitative research to identify enablers and barriers to treatment adherence.

Design This study conducted a thematic synthesis of qualitative studies.

Data sources MEDLINE, Embase, PsycINF0 via OVID, Cochrane library and CINAHL databases and grey literature sources were searched through September 2018.

Eligibility criteria We included studies conducted in individuals with $\mathrm{FH}$, and their family members, which reported primary qualitative data regarding their experiences of and beliefs about their condition and its treatment.

Data extraction and synthesis Quality assessment was undertaken using the Critical Appraisal Skills Programme for qualitative studies. A thematic synthesis was conducted to uncover descriptive and generate analytical themes. These findings were then used to identify enablers and barriers to treatment adherence for application in clinical practice.

Results 24 papers reporting the findings of 15 population samples (264 individuals with $\mathrm{FH}$ and 13 of their family members) across 8 countries were included. Data captured within 20 descriptive themes were considered in relation to treatment adherence and 6 analytical themes were generated: risk assessment; perceived personal control of health; disease identity; family influence; informed decision-making; and incorporating treatment into daily life. These findings were used to identify seven enablers (eg, 'commencement of treatment from a young age') and six barriers (eg, 'incorrect and/or inadequate knowledge of treatment advice') to treatment adherence. There were insufficient data to explore if the findings differed between adults and children.

Conclusions The findings reveal several enablers and barriers to treatment adherence in individuals with $\mathrm{FH}$. These could be used in clinical practice to facilitate optimal adherence to lifelong treatment thereby minimising the risk of CVD in this vulnerable population.

PROSPERO registration number CRD42018085946.
Strengths and limitations of this study

- This is the first thematic synthesis of the qualitative literature exploring the beliefs and experiences of individuals with familial hypercholesterolaemia to identify enablers and barriers to treatment adherence that can be targeted in clinical practice.

- Robust procedures for conducting a thematic synthesis were adopted, informed by the Cochrane Qualitative Research Methods Group guidelines and they were reported in line with the Enhancing Transparency in Reporting the Synthesis of Qualitative Research statement.

- The barriers and enablers were identified from themes which were representative of all the included studies, increasing their validity.

- While included studies were conducted across eight countries, all were within the developed world which could limit the generalisability of the findings.

\section{INTRODUCTION}

Heterozygous familial hypercholesterolaemia $(\mathrm{FH})$ is one of the most common inherited genetic disorders, estimated to affect as many as 1 in 250 individuals worldwide. ${ }^{2}{ }^{2}$ Left untreated, the exposure to chronically elevated levels of low density lipoprotein cholesterol (LDL-C) from birth confers an increased risk of cardiovascular disease (CVD), ${ }^{2}{ }^{3}$ with approximately $50 \%$ and $85 \%$ of affected women and men, respectively, experiencing a coronary event before the age of $65 .{ }^{4}$ While this risk can be significantly reduced with early detection and treatment, many affected individuals remain at higher risk of premature CVD morbidity and mortality. ${ }^{5-9}$ The most beneficial effects of treatment are evident in primary prevention before the onset of CVD. ${ }^{5}$ With diagnostic rates as low as $1 \%$ in some countries, ${ }^{11}$ current efforts are focused on identifying individuals with $\mathrm{FH}$ via screening and genetic testing programmes. ${ }^{12} 13$ Treated as 
outpatients and asked to follow lifelong treatment, it is critical to ensure that this increasing patient group are able to self-manage their disease. With many patients not reaching treatment targets, ${ }^{14-16}$ it is an area that warrants further investigation.

To improve adherence to treatment recommendations, an understanding of the factors affecting adherence is required. The American Heart Association has recognised the need to gain a deeper understanding of the experiences of individuals with $\mathrm{FH}$ before addressing the further identified research gaps. ${ }^{17}$ Preliminary research has found the beliefs and attitudes of patients with FH towards the recommended treatment exert a significant effect on their intention to engage in these behaviours. ${ }^{18} 19$ Qualitative research can provide further insight to how these beliefs and attitudes are developed and the nature by which they may influence subsequent behaviours. ${ }^{20}$ Its exploratory nature also allows for the identification of other factors influencing an individual's ability and motivation to comply with treatment. ${ }^{21} 22$

Qualitative research conducted in patients with $\mathrm{FH}$ has found illness knowledge, ${ }^{23}$ risk perception, ${ }^{24}$ a lack of symptoms ${ }^{25}$ and family history of disease ${ }^{26}$ to influence treatment adherence. However, the transferability of these findings beyond the sample they are conducted in is limited. ${ }^{27}$ Qualitative syntheses, which bring together the findings from individual qualitative studies, can be used to gain a more in-depth understanding of the issue and identify common themes which are applicable to a wider range of contexts. ${ }^{28}{ }^{29}$ It is recognised as an important source of evidence to inform healthcare interventions and policy development ${ }^{30-32}$ including those targeting treatment adherence ${ }^{33-35}$ and is advocated by the World Health Organisation (WHO) and the Cochrane Collaboration Group. ${ }^{28}{ }^{36}$ Given the limited literature concerning treatment adherence in $\mathrm{FH}$, the results of this synthesis will also be compared with the results of research investigating treatment adherence in similar medical conditions.

\section{Objectives}

1. Identify how the experiences and beliefs of individuals with FH influence their adherence to pharmacological and lifestyle treatment recommendations.

2. Explore if these findings differ between children and adults.

3. Use the findings to generate new understandings of the enablers and barriers to treatment adherence to inform clinical practice.

\section{MATERIALS AND METHODS}

The methods used for this qualitative synthesis are briefly described below with full details available in the published protocol $^{37}$ and on the PROSPERO database (registration number CRD42018085946). Minor deviations to the protocol were made, outlined in online supplementary file 1. The Enhancing Transparency of Reporting the synthesis of Qualitative research (ENTREQ) statement $^{38}$ has been followed and a checklist is available in online supplementary file 2 .

\section{Search strategy}

A comprehensive, systematic and preplanned search was conducted to find all available qualitative evidence-full details are available in online supplementary file 3 .

\section{Selection criteria}

Participants: Individuals with a clinical or genetic diagnosis of heterozygous FH. No restrictions were placed on age or history or CVD. Individuals with homozygous FH were not included.

Phenomena of interest: The experiences and beliefs of individuals with $\mathrm{FH}$, and their family members, regarding their condition, its long-term health consequences and recommended pharmacological and lifestyle change treatment.

Types of studies: Only papers reporting primary qualitative data were included. Questionnaire studies were not included. Papers reporting both quantitative and qualitative data were included if the qualitative data could be independently extracted. Multiple papers reporting findings from the same sample of participants were included if they reported unique data.

Intervention/exposure: Treatment was defined as any behavioural action undertaken by an individual in an effort to manage his/her FH diagnosis.

Setting: No restrictions were placed on the country in which study was conduction, nor the location at which data were collected from individuals.

\section{Quality appraisal}

The methodological quality of the studies was assessed using the Critical Appraisal Skills Programme (CASP) tool for reviewing qualitative research. ${ }^{39}$ As the purpose of the quality appraisal was to determine the methodological strengths and limitations of studies included in the synthesis, the lead authors of each paper were contacted to obtain further information in an attempt to overcome the recognised issued of poor reporting in qualitative research. Full details of how this tool was used are available in online supplementary file 4 .

\section{Data extraction}

Methodological and contextual information from each paper were extracted into a table designed for this review by two reviewers independently (FK, JC) after piloting in five papers. Two reviewers (FK, AS) independently reviewed all text under the results, conclusions and discussion headings of all papers, as well as any supplementary files. Any data identified to be relevant to the research questions were extracted electronically using a tool designed for this review. In instances in which multiple papers reported the findings from a single study, data from the primary paper $\mathrm{PhD}$ theses were extracted first, before supplementary publications were reviewed for any additional, unique data. Results were compared and discussed until agreement was reached. 


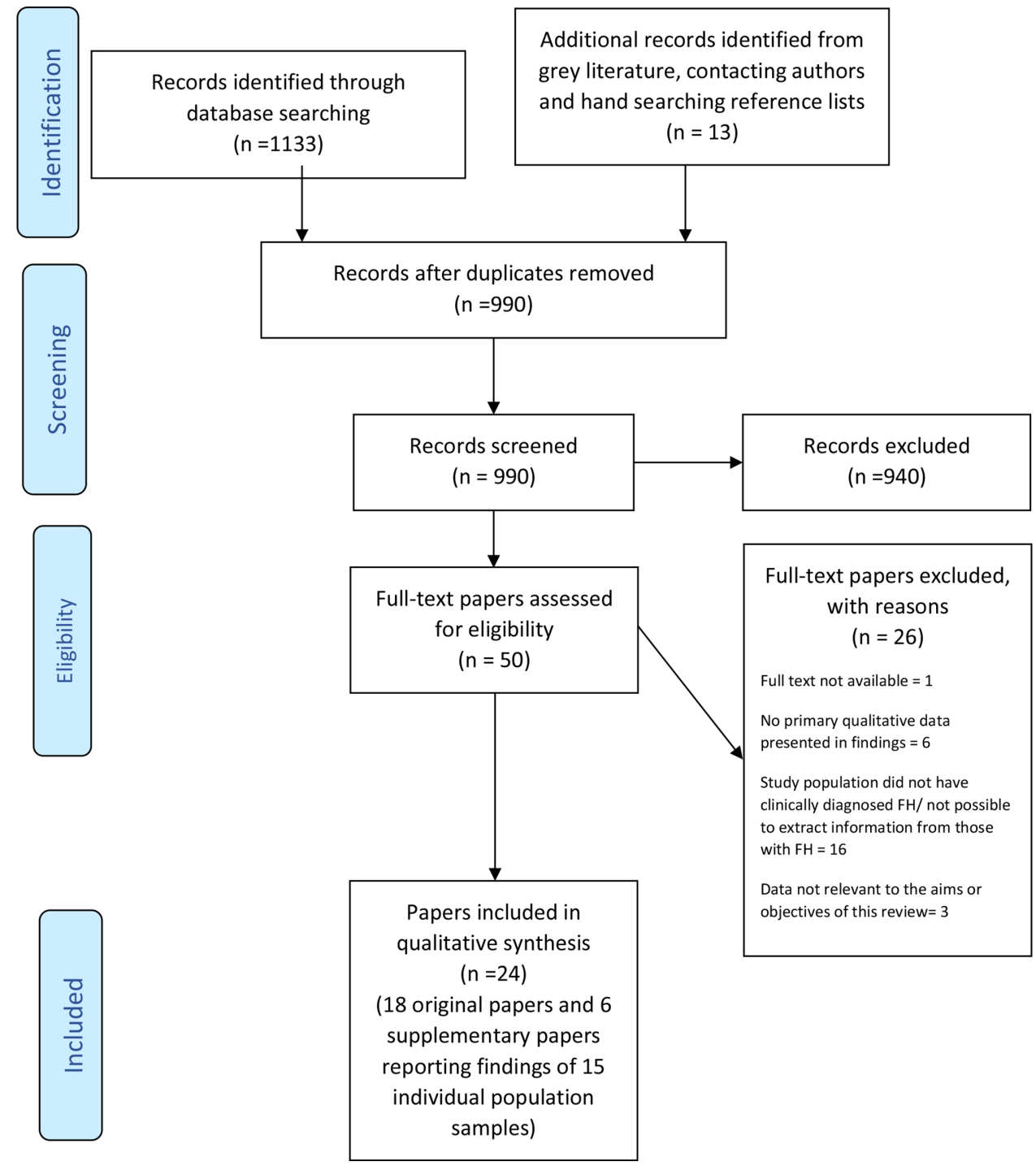

Figure 1 Preferred Reporting Items for Systematic Reviews and Meta-Analyses flow diagram. FH, familial hypercholesterolaemia.

\section{Data analysis}

Thematic synthesis, ${ }^{40}$ a widely accepted and commonly used approach in qualitative syntheses, was used. ${ }^{41}{ }^{42}$ It involved three stages: line by line coding of the extracted data, generation of descriptive themes and development of analytical themes. Using NVivo software, two reviewers (FK, AS) carried out the coding independently. The subsequent stages were carried out collaboratively between three reviewers (FK, AS, EW). To enhance transparency, full details are available in online supplementary file 5 . The findings were discussed with three clinicians (JPHS, GB, PD) currently providing care to individuals with FH to help develop feasible and relevant recommendations for clinical practice.

\section{Sensitivity analysis}

To ensure the quality appraisal results were used in a meaningful way, ${ }^{41}{ }^{43}$ post-hoc sensitivity analysis was carried out by three reviewers (FK, AS, EW) to examine the extent to which the synthesis results were affected by exclusion of poor quality papers, described in full elsewhere. ${ }^{44}$ It involved examining if any themes were lost when each paper was removed from synthesis and evaluate if there was a significant impact on the 'thickness' of findings reported within each theme. 'Thickness' refers to the depth, scope and context of findings which could influence the transferability and credibility of the results to the wider FH patient population. ${ }^{45}$ This was carried out through discussion between three reviewers (FK, AS, EW).

\section{Patient and public involvement}

Patients or members of the public were not involved in this study.

\section{RESULTS}

The titles and abstracts of 990 unique citations identified by the searches were screened, with 50 progressing to screening at the full-text level. Twenty-six papers 
were excluded at this stage due to the full text not being available $(n=1)$, no primary qualitative data being presented in the findings $(n=6)$, the study population not having a clinical diagnosis of $\mathrm{FH}$ or inability to selectively extract data from those with a diagnosis in a mixed population $(n=16)$ and data not being relevant to the aims of this review $(n=3)$. Multiple papers reporting findings from the same sample of individuals and three $\mathrm{PhD}$ papers ${ }^{46-48}$ two of which had supplementary papers published in addition to the originally reported theses, were included. Each paper was considered to be a separate primary paper and referenced separately. In total, 24 papers were included in the synthesis, comprising 18 original $^{232546-61}$ and 6 supplementary papers ${ }^{24} 26$ 62-65 reporting the findings of 15 population samples (figure 1).

\section{Characteristics of studies and participants}

In total, 264 individuals with FH and 13 family members were involved, aged 8-69 years. Seven papers ${ }^{2425} 4658596263$ reported findings from three samples which included individuals under 18 years. Four papers reported parental views of having children with FH. ${ }^{25} 565859$ Full characteristics of the included papers and samples are presented in table 1.

\section{Quality appraisal and sensitivity analysis}

Appraisal scores of papers ranged from 11 to 20 out of 20, with 11 rated high, 7 medium and 6 low (table 1 ). The most common methodological limitations uncovered were relating to ethical issues, researcher reflexivity and rigour of data analysis. Consideration of a researcher's potential influence and bias on data collection and analysis was critically examined fully in 7 papers, ${ }^{24254647586263}$ partially in $10^{23264850515557596465}$ and not addressed in 7..$^{49-54566061}$ Ethical approval was obtained, or reasons given for exemption, in all but two papers ${ }^{6061}$; however, participants were not provided adequate information about withdrawal and anonymisation of data processes in a further four papers. ${ }^{25} 495058$ The data analysis was carried out by one researcher only in seven papers ${ }^{23} 264748566465$ and it was unclear if more than one person was involved at each stage of analysis in four papers. ${ }^{51526061}$

Eight lead authors responded to our request for further information, providing information for 16 of the 24 papers. Five of the six papers rated as low quality were papers for which the author did not respond. This reflects our belief that low ratings may be reflective of poor reporting rather than poor methodology, supporting our decision not to exclude papers. The sensitivity analysis carried out found that the removal of the six poor quality papers had no significant effect on the synthesis findings-in both the descriptive and analytical themes uncovered and the depth of the findings. More detailed information of methodological and transferability issues is available in online supplementary file 4 .

\section{Data analysis}

Six analytical themes were derived from the findings captured by 20 identified descriptive themes, as displayed in table 2 alongside illustrative quotes. Table 3 shows the occurrence of the descriptive themes within the extracted data from the 24 papers. While each analytical theme has a direct influence on treatment adherence, they are not exclusive in nature and inter-theme relationships are evident as displayed in the thematic schema in figure 2. Additionally, some themes by their integrative nature had a greater influence on treatment adherence as indicated by the shaded boxes. There were insufficient data regarding children and young people to explore whether the findings differed from adults.

Seven enablers and six barriers to treatment adherence (table 4) were uncovered during the analysis of these themes and are described alongside the analytical themes below. In this section 'treatment' refers to both lifestyle and medication behaviours, unless otherwise specified.

\section{Analytical themes}

Risk assessment

Individuals lived experience of their disease, coupled with their beliefs concerning its known risks, increased or decreased their sense of vulnerability to its long-term health consequences. Knowledge of how FH had affected family members was the most prevalent factor considered by individuals when assessing their risk. Individuals with lived experience of a family member being ill or dying prematurely due to $\mathrm{FH}$ had a heightened sense of risk. $^{46484952555658-62}$ Individuals unaware of $\mathrm{FH}$ in their families or with family members living a life unaffected by its consequences perceived themselves at lower risk $^{46} 52565861$ 62. 'My dad's now in his 70s...it's not something I feel particularly threatened about having. ${ }^{56}$

As FH does not 'make you feel ill' ${ }^{52}$ individuals found having FH 'easy to forget, and easy not to take seriously. ${ }^{47}$ This was salient among younger individuals without existing CVD symptoms ${ }^{23254748585965}$ for whom '... cholesterol always comes last. It will never be a focus until something happens to me. ${ }^{47}$ Older individuals who had lived through, or were currently experiencing CVD, perceived themselves at higher risk. ${ }^{23} 566162$ Others framed their perception of risk in the context of the risk they believed other diseases presented, concluding that FH health consequences were not as serious ${ }^{23} 474851535461$ : 'I didn't think it was life threatening, like being told you've got cancer., 23

For the majority of individuals, their risk assessment led to a perception that $\mathrm{FH}$ did not present a great risk to their current or long-term health. ${ }^{23} 47-49515659-61$ This mismatch between the perceived and actual risk has been identified as a barrier to treatment adherence.

\section{Perceived personal control of health}

Individuals acknowledged the threat that $\mathrm{FH}$ posed to their health, but there was a widely held belief that they had the ability to modify their own personal risk. ${ }^{24} 47495153-62$ 


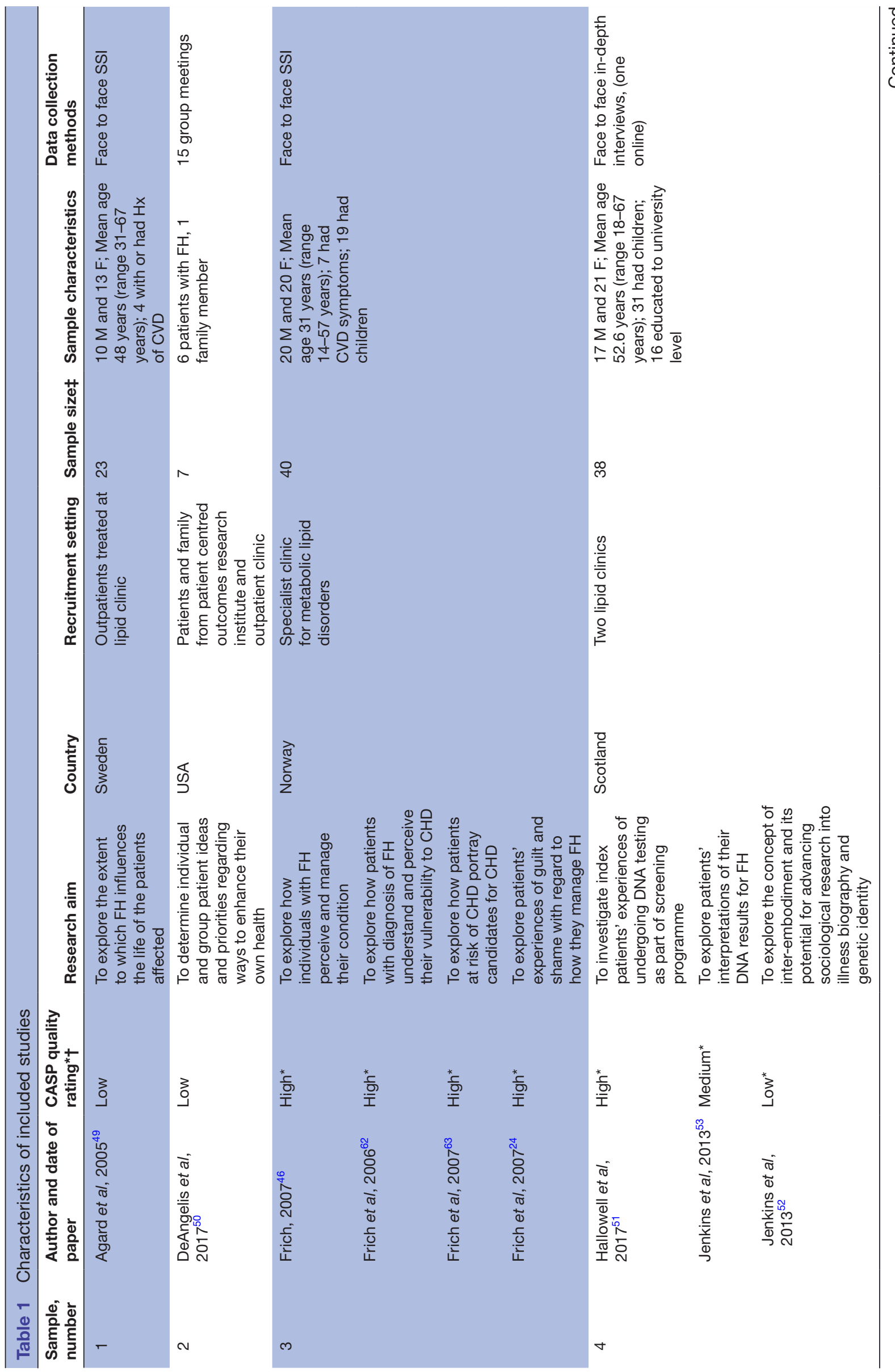




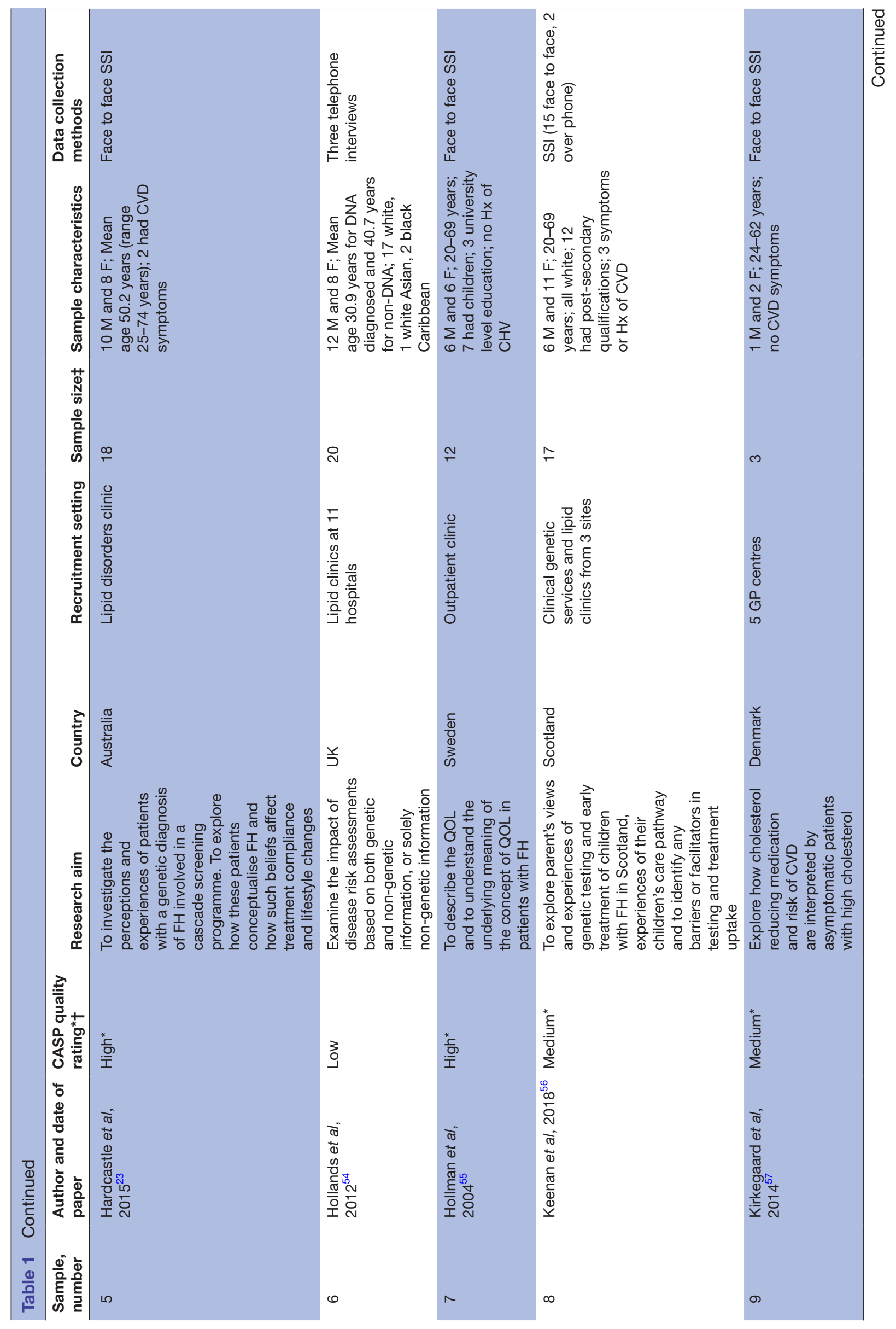

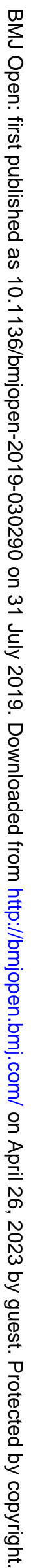



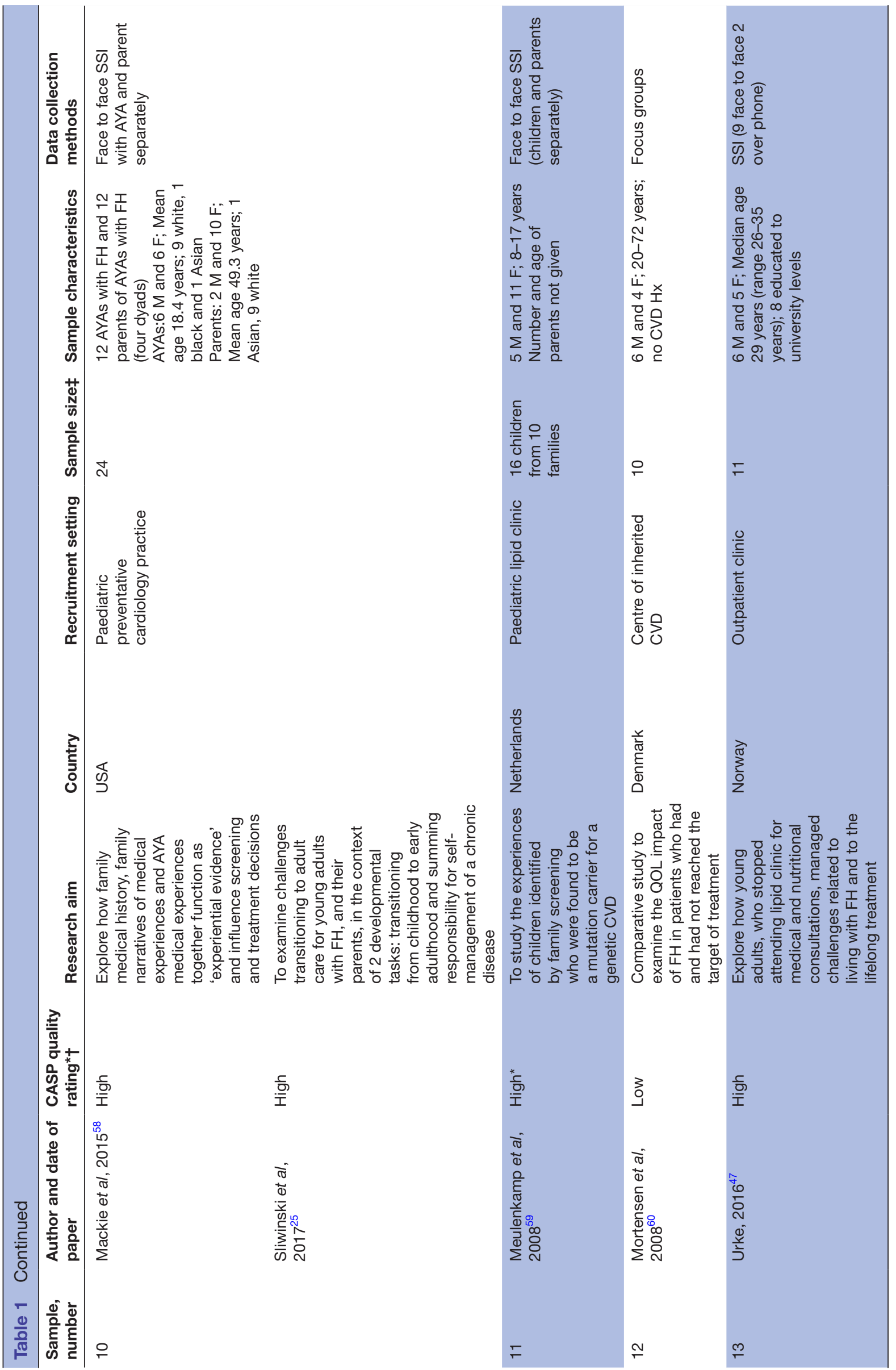

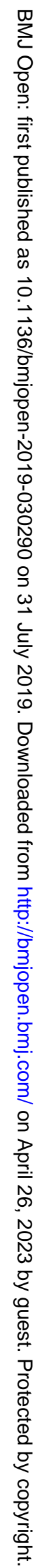




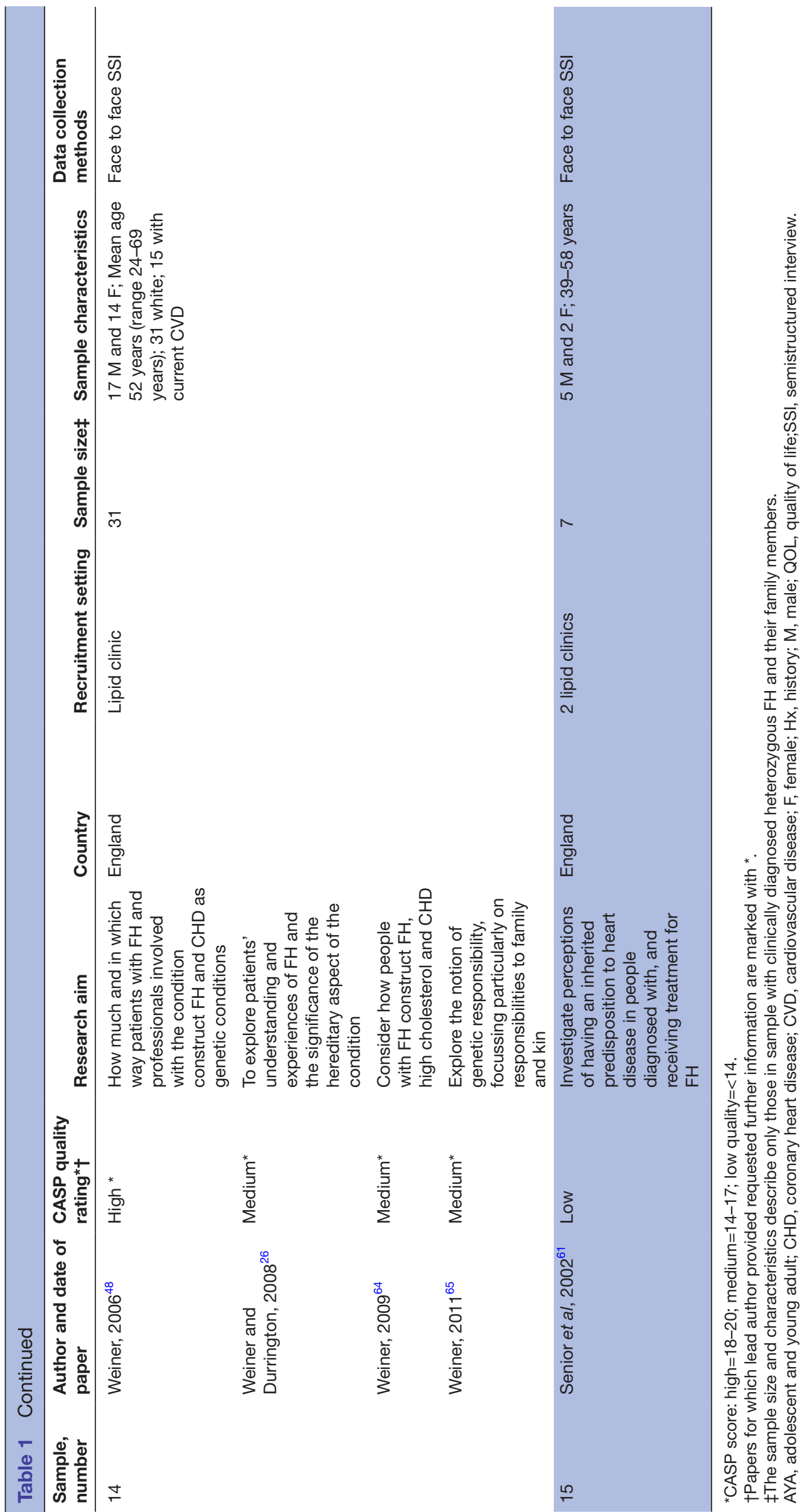

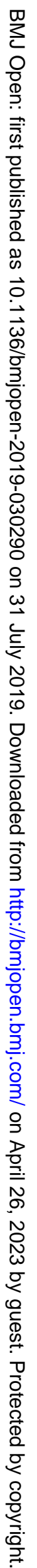


Table 2 Analytical themes and their composite descriptive themes with illustrative quotes

\begin{tabular}{lll} 
Analytical theme & Descriptive themes & $\begin{array}{l}\text { Illustrative quotes from participants (first } \\
\text { order) }\end{array}$ \\
\hline Risk assessment & FH is a silent disease & $\begin{array}{l}\text { 'Not a condition that has any symptoms, } \\
\text { that makes you feel ill or anything. }\end{array}$ \\
\end{tabular}

Family history modifies perception of FH-related threat to health

$\mathrm{FH}$ is not as threatening to 'Its not that bad....Its not like having health as other conditions something like Huntington's or something like that. ${ }^{.5}$

Perceived personal control $\mathrm{FH}$ is a manageable of health

condition got past sixty. ${ }^{.53}$ 'Well it's treatable isn't it by diet and dru
Individuals feel personally 'It means you could be in danger of like responsible for managing what could possibly happen like in the their $\mathrm{FH}$ future if you don't change anything. ${ }^{, 58}$

FH medication is effective 'I believe that as I am taking the pills that my risk of heart attack is no greater than anyone else of my age or weight. ${ }^{, 61}$

FH lifestyle treatment viewed as less important than medication

$\begin{array}{ll}\text { Disease identity } & \text { Importance of } \\ \text { establishing that hig } \\ \text { cholesterol levels ar } \\ \text { self-inflicted } \\ \text { Receiving genetic } \\ \text { diagnosis provides } \\ \text { certainty }\end{array}$

The influence of family much dieting or exercise I do...so it can only be reduced through medication. ${ }^{48}$

'It enables me to emphasise that it is not my fault, that it's something inherited. ${ }^{162}$ I had an answer to what was quite a surprising medical condition that I had... so at least I know now and can take preventative measures. ${ }^{, 54}$

Desire to protect children 'We want to help him...(so) we have
'I'm not going to get past sixty. Dad never

'Well it's treatable isn't it by diet and drugs.

'I could never get that down no matter how

'I guess it is a relief in a funny way because decided to give him statins until he is 16 ... we've covered him until he's old enough to decide for himself. ${ }^{56}$

Parental influence on treatment related behaviours

'My parents, specifically my mom, were really integral in teaching us types of food to eat. ${ }^{25}$

$\mathrm{FH}$ and its treatment become normalised within relatively good diet and good habits and families routines, it makes it easier. ${ }^{, 47}$ (second order)

'The majority of interviewees did not look on the condition as a disease... If they were not affected by a cardiac disease. they regarded themselves as healthy. ${ }^{49}$

'To them, reaching the age of death of a parent with $\mathrm{FH}$ was anticipated with fear of having a heart attack themselves. ${ }^{, 60}$

They mentioned conditions with more drastic consequences such as allergies, epilepsy or diabetes. ${ }^{47}$

'FH carrier children demonstrated high feelings of control over their condition. ${ }^{59}$

'FH patients have a strong desire to empower themselves in order to improve their own health. ${ }^{50}$

'Preventative medical treatment built confidence in the potential for living a long life. ${ }^{55}$

'Many tended to devalue the importance of lifestyle changes in controlling $\mathrm{FH}$ and place their hope in medication. ${ }^{23}$

'They always described $\mathrm{FH}$ as a hereditary condition to underline that their cholesterol issues were not due to unhealthy lifestyle. ${ }^{, 60}$

'It provided an aetiological explanation and diagnostic label, confirmed current risk management practices...,24

'In fact, the main concern for the affected parents appeared to be the well-being of their children...49

'AYAs expressed how their perceptions of their parents experience have influenced their perceptions of the respective treatment options. ${ }^{, 58}$

'FH carrier children typically reported it had become habit to maintain a healthy, non-fat diet. Commonly the whole family, including the non-carriers, kept to the same diet restrictions. ${ }^{, 59}$

'The doctors presentation of $\mathrm{FH}$, however, 'My daughter. I don't think she really understood what (high cholesterol) really meant until she came here and talked with doctor. $^{, 58}$

Inadequate and/or incorrect knowledge about $\mathrm{FH}$ and treatment

Concerns about side effects of FH medication 'in the newspapers, the stories that you cut out butter, red meat, etc, and you'll be okay., ${ }^{61}$

'Would I be able to have children at all after taking all these medicines for years? ${ }^{, 49}$ influenced all patients perceptions of the risk and severity of the diagnosis. ${ }^{60}$

'Many informants still had unanswered questions or were felt to lack relevant knowledge. ${ }^{, 49}$

'Parents reported having strong concerns about statin treatment in children, not only because of their long-term safety but also potential side effects. ${ }^{56}$ 
Table 2 Continued

\begin{tabular}{lll}
\hline Analytical theme & Descriptive themes & $\begin{array}{l}\text { Illustrative quotes from participants (first } \\
\text { order) }\end{array}$ \\
\hline $\begin{array}{l}\text { Incorporating treatment } \\
\text { into daily life }\end{array}$ & $\begin{array}{l}\text { FH and its treatment does 'You don't have to plan your life around it. } \\
\text { not have big impact on life } \\
\text { You don't have to wonder, can you have } \\
\text { children or not. }\end{array}$
\end{tabular}

Balancing FH treatment with other competing priorities

Lifestyle advice treatment is restrictive and difficult to follow

Social implications of following $\mathrm{FH}$ treatment

Desire for further support and guidance
'Our two children, who were often ill.....My husband...travelled all the time, so I almost had more than I could put up with at that moment. ${ }^{, 62}$

'I've changed my diet as much as I can... don't want to bother too much and speculate, live an unworthy life and diet at the age of seventy. l'd rather be happy and die when I'm fifty. ${ }^{24}$

'Some people comment on the things I eat. And then I'm like 'well actually I have to eat this because I've got FH and I have to watch my diet.'54

I think having the resources (would make it easy to adhere to lifestyle treatment)... like seeing a nutritionist that can give you options....,25
Illustrative interpretations from authors (second order)

'FH was not viewed as a significant burden, but more of a lifestyle adjustment, involving a healthy diet, exercise, and statin treatment from an early age. ${ }^{56}$

'Young adults also articulated challenges maintaining diet and exercise regimes while adjusting to a new routine and environment at college or in workforce. ${ }^{, 25}$

'Making dietary changes had been the worst aspect of their condition, and this included people who already had CHD. ${ }^{62}$

' 10 young adults articulated how concern over peers' opinions or overt peer pressure-restricted social activities centred around eating. ${ }^{25}$

'...expressed a desire to be able to access educational resources in one place and for a way to reach out to others who could provide solidarity, comfort and aid with management of $\mathrm{FH} .{ }^{, 50}$

AYA, adolescent and young adult; CHD, cardiovascular heart disease; HCP, healthcare professional.

They recognised that this required active engagement with treatment ${ }^{23-25} 47$ 49-51 53-56586162 and held themselves accountable for managing their disease $23-2547-51$ 53-58 60-62 experiencing a 'bad conscience' ${ }^{49}$ and 'guilt' ${ }^{63}$ when they did not meet the expectations they had set themselves. Treatment was perceived to be effective $2447495153-62$ with individuals viewing $\mathrm{FH}$ as 'treatable ${ }^{48}$ and 'controllable'. ${ }^{23}$ In particular, medication was regarded by individuals to be a mandatory and effective component of treatment. ${ }^{24} 474951$ 53-62 They believed FH could be 'solved'59 with medication and lead to achievement of cholesterol levels 'like most people'. ${ }^{23}$ While individuals spoke of their efforts to change their lifestyle behaviours, ${ }^{24} 25474951$ 53-62 many believed their cholesterol levels would not be 'radically changed'61 by doing so ${ }^{47485860}$ as 'doesn't matter what I eat or how much exercise I'm still going to have high cholesterol without tablets'. ${ }^{23}$

This confidence in the ability to successfully self-manage their condition was identified as an enabler to treatment adherence. The perceived effectiveness of medication led to a devaluing of the importance of following lifestyle treatment, 234748575860 and this prioritisation of medication was identified as a barrier to adhering to lifestyle treatment.

\section{Disease identity}

Individuals placed great importance, especially in social situations, to emphasis that they were "not to blame" 60 for their high cholesterol.24 26485051535457606163 High cholesterol was associated with unhealthy lifestyles and individuals wished to distance themselves from this negative connotation. ${ }^{24} 485457606163$ A positive genetic test provided 'a definitive', 51 rather than a possible, explanation for their high cholesterol ${ }^{5053} 54$ and positively influenced individuals' perceptions and behaviours. ${ }^{24} 50515354$ If individuals had been following treatment of their own volition before the diagnosis, it helped 'reaffirm their commitment ${ }^{53}$ to treatment. ${ }^{51} 54$ If they had been previously unaware of their condition, it prompted them to seek treatment ${ }^{5356}$ : 'I know now and can take preventative measures'. 54 Therefore, receiving a formal diagnosis was identified as an enabler to treatment adherence as being given a medical explanation empowered individuals to take control of their condition through engaging with treatment.

\section{Family influence}

Parents expressed a high level of concern about the wellbeing of their affected children 2548505153565859 and this parental responsibility to care for children was identified as another enabler of treatment adherence. They assumed responsibility to ensure their children adhered to medical and lifestyle treatment, ${ }^{2548505153565859}$ taking action to 'bring them up with healthy eating habits ${ }^{51}$ and 'make sure that they take their medication'. 48 This involvement was reflected in the finding of individuals attributing their current treatment knowledge and behaviours to their parents ${ }^{47-49}$ : 'everything I've learnt from home'. ${ }^{47}$ Parents also made treatment-related decisions on their behalf ${ }^{254850535859}$ until they were 'old enough to decide.' 56 As such, the early adulthood years presented a challenge for treatment adherence as the young adults transitioned 


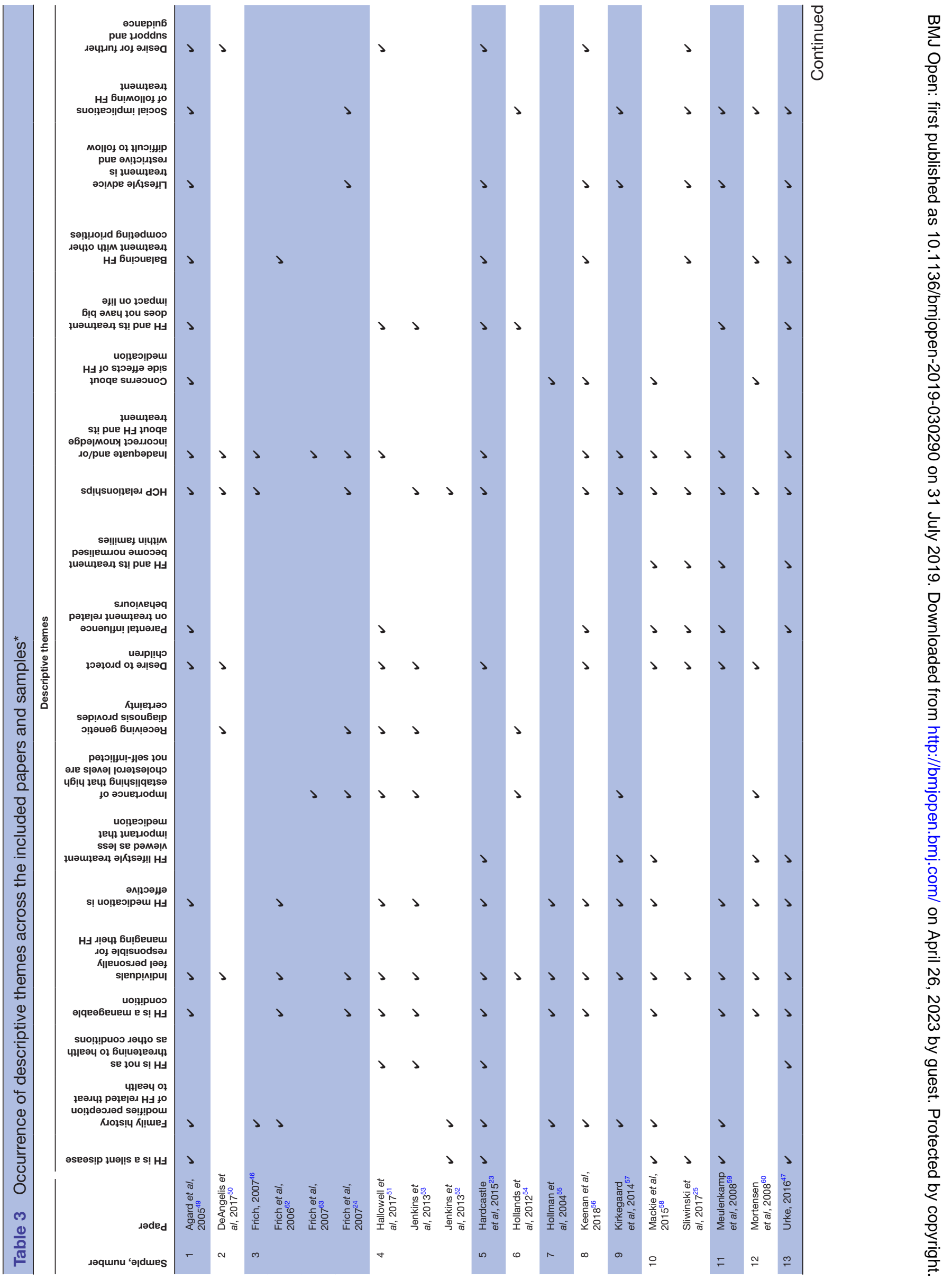



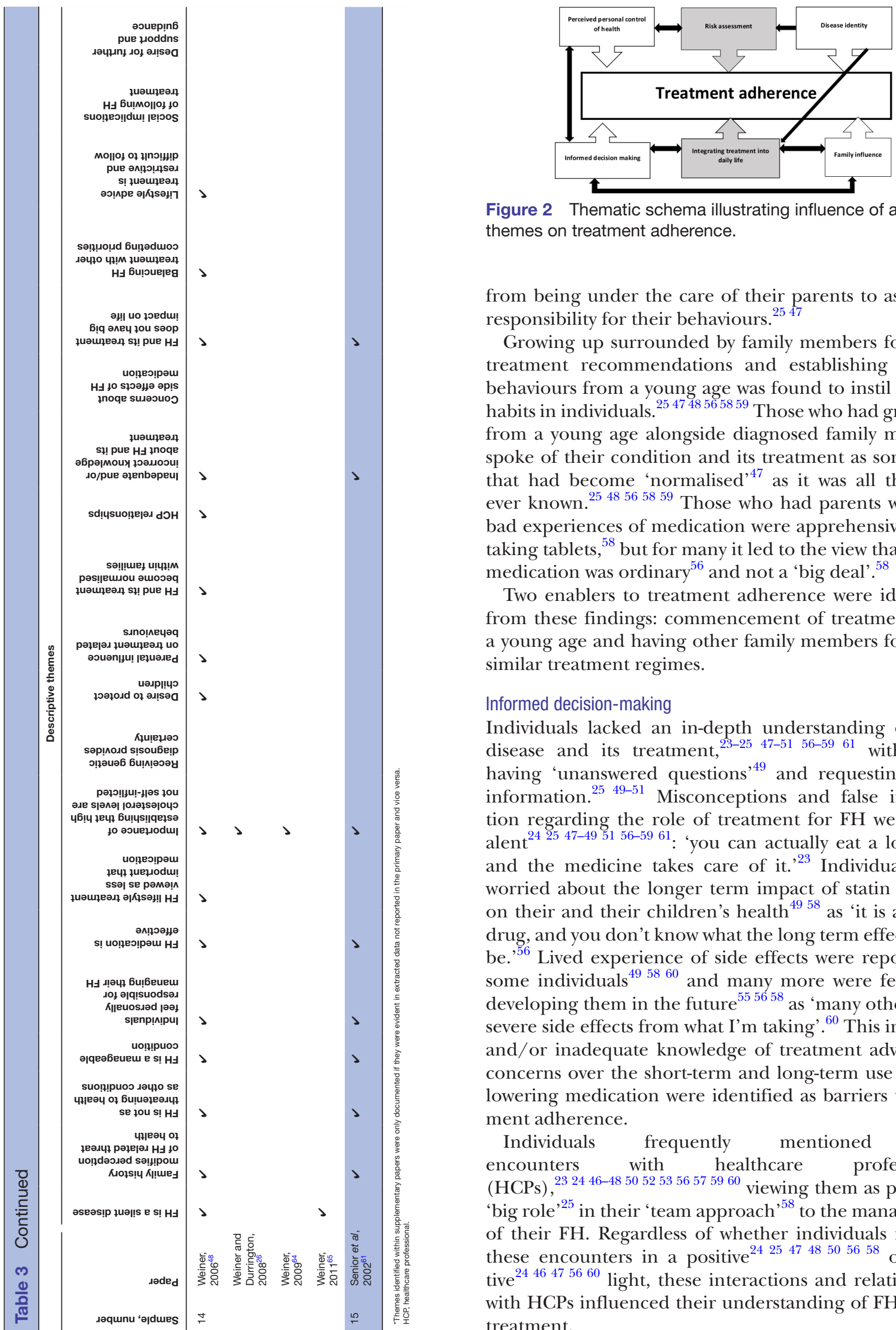

Figure 2 Thematic schema illustrating influence of analytical themes on treatment adherence.

from being under the care of their parents to assuming responsibility for their behaviours. ${ }^{25} 47$

Growing up surrounded by family members following treatment recommendations and establishing healthy behaviours from a young age was found to instil lifelong habits in individuals. ${ }^{25448565859}$ Those who had grown up from a young age alongside diagnosed family members spoke of their condition and its treatment as something that had become "normalised ${ }^{47}$ as it was all they had ever known. 2548565859 Those who had parents who had bad experiences of medication were apprehensive about taking tablets, ${ }^{58}$ but for many it led to the view that taking medication was ordinary ${ }^{56}$ and not a 'big deal'. ${ }^{58}$

Two enablers to treatment adherence were identified from these findings: commencement of treatment from a young age and having other family members following similar treatment regimes.

\section{Informed decision-making}

Individuals lacked an in-depth understanding of their disease and its treatment, ${ }^{23-25}$ 47-51 56-59 61 with many having 'unanswered questions' ${ }^{49}$ and requesting more information. ${ }^{25}{ }^{49-51}$ Misconceptions and false information regarding the role of treatment for $\mathrm{FH}$ were prevalent $^{24} 25$ 47-49 51 56-59 61: 'you can actually eat a lot of fat and the medicine takes care of it. ${ }^{23}$ Individuals were worried about the longer term impact of statin therapy on their and their children's health ${ }^{498}$ as 'it is a recent drug, and you don't know what the long term effect could be. ${ }^{56}$ Lived experience of side effects were reported by some individuals ${ }^{49} 58$ and many more were fearful of developing them in the future ${ }^{555658}$ as 'many others have severe side effects from what I'm taking. ${ }^{60}$ This incorrect and/or inadequate knowledge of treatment advice and concerns over the short-term and long-term use of lipid lowering medication were identified as barriers to treatment adherence.

Individuals frequently mentioned their encounters with healthcare professionals (HCPs), ${ }^{23} 2446-4850525356575960$ viewing them as playing a 'big role" ${ }^{25}$ in their 'team approach's8 to the management of their FH. Regardless of whether individuals recalled these encounters in a positive 24254748505658 or negative ${ }^{24} 46475660$ light, these interactions and relationships with HCPs influenced their understanding of $\mathrm{FH}$ and its treatment. 
Table 4 Identified enablers and barriers to treatment adherence

\begin{tabular}{ll} 
Enablers & Barriers \\
\hline Other family members following treatment regime & Mismatch between perceived and actual risk \\
Commencement of treatment from a young age & Concerns over the use of lipid lowering medication \\
Parental responsibility to care for children & Prioritisation of medication over lifestyle treatment \\
Confidence in ability to successfully self-manage their condition & Lifestyle treatment is difficult to comply with \\
Receiving formal diagnosis of FH & Prioritisation of other life events \\
Practical resources and support for following lifestyle treatment & Inadequate and/or incorrect knowledge of treatment advice \\
A positive relationship with healthcare professional & \\
\hline
\end{tabular}

$\mathrm{FH}$, familial hypercholesterolaemia.

\section{Integrating treatment into daily life}

Individuals did not feel they had to make many changes to their everyday life as a result of their diagnosis. ${ }^{2347-49515461}$ Their disease did not hinder them from 'living the life they wanted ${ }^{47}$ or require consideration when making life decisions ${ }^{23} 47495461$ such as having children. ${ }^{48}{ }^{51}$ However, when faced with other commitments, such as family and career obligations, individuals found it more difficult. $^{23254749546062}$ During these periods, individuals tended to be less focused on managing their disease viewing it as something they could pick up again when they had more time and energy. ${ }^{2325475662}$ This prioritisation of other life events over the self-management of condition was identified as a barrier to treatment adherence.

The treatment recommendations were perceived to be simple to follow and to have little impact on their quality of life (QOL). ${ }^{23} 47-4951$ 53-56 61 However, this perception is in stark contrast to the actual lived experiences of following treatment-especially the lifestyle recommendations. Dietary advice was perceived to be restrictive and interpreted by individuals to mean they could not eat their favourite foods 242547485759 or enjoy social occasions 242554575960 : 'I won't bother eating food I don't like, just to follow a certain diet' ${ }^{47}$ Additionally, individuals were concerned about the opinions of their peers in social situations in which they felt they had to make certain dietary choices. ${ }^{25} 47485960$ These findings were prominent among younger individuals. ${ }^{25} 4759$ As a result, the dietary advice was the 'most difficult aspect' 49 of treatment, with many reporting they struggled to follow them at all times. ${ }^{23-254748575960}$ This finding of dietary advice being perceived as difficult to follow was identified as a barrier to adherence.

Reflective of the difficulties faced when trying to follow treatment guidelines, individuals expressed a need for additional information ${ }^{23495056}$ and 'guidelines in order to help you start that change'. ${ }^{25}$ Some sought additional information from their HCPs, 2325495056 while others called for practical advice and educational resources, 25495056 as 'everyone knows the theory, but putting it to practice is quite hard'. ${ }^{23}$ From this, practical resources and support for following lifestyle treatment advice was identified as an enabler to treatment adherence.

\section{DISCUSSION}

This synthesis has produced new insights into the factors influencing treatment adherence in FH which have implications for clinical practice and future research.

We found that individuals did not perceive $\mathrm{FH}$ as a threat to their health except in those who had experienced symptoms of CVD or had a family history of FH-related CVD, as previously reported by others. ${ }^{66-69}$ This low perception of risk may be the result of the disease being relatively symptomless and the adverse consequences too far in the future to comprehend. This idea is reinforced by studies reporting heightened perceived risk among older individuals $^{70}$ and young adults perceiving their health to be average or above that of the general population. ${ }^{16}$ The minimal threat to health may explain the findings that being diagnosed with $\mathrm{FH}$ does not increase psychosocial dysfunction in children, ${ }^{71} 72$ nor negatively impact on self-reported QOL or rates of depression and anxiety in adults. ${ }^{73-76}$ While these findings are positive, individuals who do not view their disease as a serious threat may be less motivated to adhere to treatment, which may explain the findings of higher self-reported medication adherence in older individuals ${ }^{77} 78$ and high non-adherence rates in individuals under 36 years. ${ }^{79}$ These findings are concerning as individuals who do not adhere fully to treatment have been found to have higher levels of LDL-C. ${ }^{77} 7980$ Furthermore, while treatment has substantially reduced the risk of CVD, individuals still remain at a higher risk than the general population. ${ }^{9} 8182$ This may be a consequence of LDL-C targets not being met by large numbers of treated adults ${ }^{1516798083}$ and children ${ }^{8485}$ and/or the presence of other risk factors independently associated with CVD. ${ }^{8687}$

Our findings suggest this low-risk perception may be mediated by beliefs that the risks are avoidable through effective treatment, in line with previous research. ${ }^{16667288}$ These beliefs have been found to positively influence attitudes towards medication, increasing self-reported intentions to comply with medication ${ }^{19}$ and rates of adherence. ${ }^{89}$ However, individuals' attitudes toward treatment behaviours may have a greater influence on their intention to engage in treatment than their beliefs. ${ }^{18}$ Our findings of negative attitudes towards 
certain aspects of treatment are therefore important to explore. We found individuals to perceive dietary recommendations as restrictive and impacting on their QOL, as have others. ${ }^{72}{ }^{90}$ Some also believed they were unnecessary if taking medication, likely explaining low uptakes of lifestyle treatment compared with medication. ${ }^{6691} \mathrm{We}$ also found negative attitudes towards medication due to side effects and anxieties about long-term safety, similar to others. ${ }^{16} 8392$ In contrast to these studies, we found anxiety about the development of side effects and complications of long-term use to be more prevalent than lived experience of side effects. These negative attitudes are surprising as the dietary recommendations do not differ substantially from those for the general population and the safety and tolerability of statins have been demonstrated in adults ${ }^{93}$ and children. ${ }^{94-96}$

Our finding of widespread inadequate knowledge of the treatment recommendations may explain the negative attitudes. It has been reported previously that awareness of the role of PA in treatment is low ${ }^{97}$ and while individuals are mindful of the need for dietary treatment, little is known about the depth of this knowledge. ${ }^{72} 9097$ This finding may be the result of the inconsistency in treatment advice provided with many not receiving the recommended lifestyle advice ${ }^{919899}$ or medication treatment ${ }^{83859198100101}$ and for those that do, it is often not provided by HCPs with specialist $\mathrm{FH}$ knowledge. ${ }^{91} 99$ As a result, we found many individuals are left wanting more information about treatment, in line with previous research. ${ }^{91}{ }^{97}$ This is concerning as many report using the internet to search for such information ${ }^{91}$ which cannot be easily regulated and may be fuelling our further finding of a high prevalence of incorrect knowledge. Furthermore, individuals may be falsely interpreting negative media coverage of statin medication ${ }^{102}$ to be relevant to their condition. This may be negatively influencing adherence to treatment as concerns about general medication overuse have been found to be heavily influential in shaping attitudes towards $\mathrm{FH}$ medication ${ }^{19}$ Ensuring individuals have a comprehensive and factually correct understanding of the treatment recommendations is therefore essential to optimise adherence.

As this synthesis highlighted that parents take responsibility for their childs' treatment, it is important to ensure they are knowledgeable about the recommendations to help their children develop healthy habits from a young age. Previous research has found that children who follow dietary guidelines from a young age have more positive attitudes towards this aspect of treatment ${ }^{71}$ and have improved dietary intakes in childhood ${ }^{103-105}$ which are maintained into young adulthood. ${ }^{106}$ Furthermore, forgetfulness is frequently reported as a reason for medication non-adherence $\mathrm{e}^{167277788092}$ and starting treatment at a young age may help overcome this by instilling a routine, as found by others. ${ }^{107}$ It is also important to ensure that when individuals reach an age where they become responsible for their own care, they themselves are equipped with the relevant knowledge to continue to make informed decisions. While there were insufficient data to draw conclusions about best practice for this age group, it appears that transitioning from living at home, adjusting to new routines and prioritising other things in life are common barriers to be targeted..$^{25} 47$

Our findings also highlight the importance of receiving a genetic confirmation of $\mathrm{FH}$. Receiving a medical diagnosis empowered individuals to take control of their condition, providing motivation to continue or commence medication and lifestyle treatments. The positive influence of diagnosis on medication efficacy beliefs and adherence has been reported in previous research. ${ }^{6768108}{ }^{109}$ However, in contrast to our findings, it has been reported that positive genetic results have either no effect ${ }^{68}$ or weaken beliefs ${ }^{108}$ regarding the efficacy of lifestyle treatment. However, in both cases the changes in beliefs did not have a negative impact on their actual behaviours. Given our further finding that individuals find medical diagnosis useful in social situations, a common identified barrier to adhering to dietary recommendations, it may be that genetic diagnosis exerts positive effect on adherence beyond its influence of illness and treatment beliefs.

\section{Strengths and limitations}

Our thematic synthesis adhered to ENTREQ guidelines and used transparent and robust methodology. The comprehensive search strategy, involvement of more than one researcher at each stage of analysis, input from clinicians to corroborate the interpretation of the results and detailed appraisal of the included studies strengthen our findings. The analytical themes generated were produced from descriptive themes that were each evident across a large number of the included papers. The synthesis included data from 264 individuals with FH and 13 family members across 8 countries, encompassing a wide range of ages, duration of diagnoses, primary and secondary CVD prevention and regional differences in healthcare provision. However, all individuals were from developed countries, the majority had high education levels and there were few from ethnic minority groups. This may limit the generalisability of the findings to all individuals with FH. Furthermore, the majority were recruited from lipid clinics and their beliefs may not reflect those opting out of treatment for their condition. Lastly, there were insufficient papers to explore if the factors influencing treatment adherence differ between adults and children with $\mathrm{FH}$ and care should be taken when extrapolating results to younger individuals.

\section{Implications for clinical practice}

We have identified seven enablers and six barriers to treatment adherence (table 4) to be considered by any HCP delivering advice to individuals with $\mathrm{FH}$ and have produced the following 12 suggestions for clinical practice: 
1. Ensure individuals are aware of the risk to their health, without instilling fear through emphasising the effectiveness of medical and lifestyle treatment.

2. Where possible, ensure all individuals receive genetic confirmation of their condition.

3. Communicate that despite the asymptomatic nature of the condition, adhering to treatment from a young age will deliver the greatest benefits to health.

4. Discuss medication within an FH context, emphasising its necessity and distinguishing it from the use of medication in treatment of other causes of high cholesterol.

5. Provide reassurance that medication is safe and side effects uncommon, with reference to relevant clinical guidelines indicating their safety for use by children highlighted to parents.

6. Inform patients that side effects are specific to each type of medication and encourage discussion of any problems so alternative medications can be offered.

7. Communicate dietary advice as being a lifestyle change rather than a restrictive diet with advice tailored to the individual needs and preferences of each individual.

8. Ensure individuals have a factually correct understanding of the dietary recommendations and provide credible resources individuals can access if they require further support or guidance.

9. The benefits of adhering to lifestyle treatment for management of their disease and their overall well-being should be revisited at each clinic appointment.

10. Treatment should begin early, with parents advised that prior to medication, dietary recommendations can be followed from the age of 5. Non-affected family members can also be encouraged to follow guidelines, facilitating a family-based approach to aid adherence.

11. Treatment advice to be provided in family-based clinics if possible, or ensure adult and paediatric services are closely linked.

12. Adolescent patients to be offered opportunity to transition to an adult clinic between the ages of 16 and 18 to take responsibility for their own treatment before they leave home.

\section{Comparison with treatment adherence in similar medical} conditions

The limited literature regarding treatment adherence in FH makes comparison of findings with the present synthesis difficult. However, extensive research has been conducted into treatment adherence for other chronic conditions which are also asymptomatic in the early stages such as hypertension, high cholesterol from non-genetic conditions and type 2 diabetes mellitus, for which treatment adherence rates are also low. ${ }^{110111}$ While it is beyond the scope of this review to compare and contrast the findings in detail, overall the enablers and barriers were similar to those found to exist for individuals following treatment for these similar conditions. For example, negative perceptions of medication, beliefs that treatment is not necessary due to lack of symptoms, medication side effects and a lack of knowledge about treatment and/or disease were identified as barriers to adherence for those advised treatment to manage risk factors for the primary and secondary prevention of CVD. ${ }^{112-114}$ Furthermore, similar findings have been reported in individuals with type 2 diabetes mellitus. ${ }^{115-117}$ A unique finding of the present synthesis, however, was that starting treatment from a young age and being surrounded by other family members following treatment facilitates adherence. This is reflective of the genetic inheritance pattern in which an individual will always have one affected parent, which is uncommon in other chronic conditions. Although support from family members, and the involvement of parents, has been identified as an enabler to treatment adherence for individuals with type 2 diabetes mellitus, ${ }^{115} 118119$ the adherence behaviours that parents with FH model to family members are of particular importance in the treatment of $\mathrm{FH}$.

\section{Future research}

With treatment most effective when started at a young age, ${ }^{6} 1085$ and our findings of a positive effect on later life adherence, further qualitative research exploring the perspectives of children is required to allow HCPs to tailor advice to support maximal adherence during this crucial period. The findings of widespread inadequate and/or incorrect knowledge of the treatment recommendations warrant investigation into what advice is being given and by whom. As individuals who have self-selected to receive treatment have concerns about medication, it is likely that there are many individuals opting not to receive treatment for themselves or their child due to these concerns. Future research is needed to explore their perceptions to develop effective interventions that could encourage them to seek treatment.

\section{CONCLUSIONS}

This qualitative evidence synthesis has systematically reviewed and synthesised the available evidence concerning the experiences and beliefs of individuals with $\mathrm{FH}$ regarding their condition and its treatment. It has uncovered several enablers and barriers that are to be used in clinical practice to facilitate optimal treatment adherence in this high-risk clinical population group. It has also highlighted significant research gaps which need to be addressed to gain a more comprehensive understanding of how these individuals can be supported to adhere to lifelong treatment.

\section{Author affiliations}

${ }^{1}$ The National Institute for Health Research (NIHR), Bristol Biomedical Research Centre (BRC), Nutrition theme, University Hospitals Bristol NHS Foundation Trust and the University of Bristol, Bristol, UK

${ }^{2}$ Psychology Department, Bath Spa University, Bath, UK

${ }^{3}$ Department for Health, University of Bath, Bath, UK 
${ }^{4}$ Department of Clinical Biochemistry, University Hospitals Bristol NHS Foundation Trust, Bristol, UK

${ }^{5}$ Population Health Science, Bristol Medical School, University of Bristol, Bristol, UK

Acknowledgements We would like to thank Catherine Borwick (Research Engagement Librarian) and Dr Alison Gregory (Research Fellow) at The University of Bristol for their expertise and assistance in the development of this evidence synthesis. We would also like to thank Dr Paul Downie (Consultant at University Hospitals Bristol and Royal United Hospitals Bath NHS Foundation Trusts) for his input into translating the findings into clinical recommendations.

Contributors FK and RP devised and carried out the search strategy. FK, RP, FEL and JPHS carried out the study screening and selection stage. FK and JC carried out the study characteristic extraction stage. FK and AS carried out the results data extraction, quality appraisal, data analysis and interpretation. EW also carried out the data analysis and interpretation stages. $\mathrm{AH}$ contributed to the development and presentation of the qualitative methodology and results. FK, JPHS and GB translated findings into clinical implications. FK prepared the manuscript. All authors reviewed the manuscript and approved the final version.

Funding This evidence synthesis is funded by the National Institute for Health Research NIHR Bristol Biomedical Research Centre (Nutrition theme) at University Hospitals Bristol NHS Foundation Trust and The University of Bristol.

Competing interests None declared.

Patient consent for publication Not required.

Provenance and peer review Not commissioned; externally peer reviewed.

Data availability statement All data relevant to the study are included in the article or uploaded as supplementary information.

Open access This is an open access article distributed in accordance with the Creative Commons Attribution 4.0 Unported (CC BY 4.0) license, which permits others to copy, redistribute, remix, transform and build upon this work for any purpose, provided the original work is properly cited, a link to the licence is given, and indication of whether changes were made. See: https://creativecommons.org/ licenses/by/4.0/.

\section{REFERENCES}

1. Akioyamen LE, Genest J, Shan SD, et al. Estimating the prevalence of heterozygous familial hypercholesterolaemia: a systematic review and meta-analysis. BMJ Open 2017;7:e016461.

2. Benn M, Watts GF, Tybjærg-Hansen A, et al. Mutations causative of familial hypercholesterolaemia: screening of 98098 individuals from the Copenhagen general population study estimated a prevalence of 1 in 217. Eur Heart J 2016;37:1384-94.

3. Wong B, Kruse G, Kutikova L, et al. Cardiovascular disease risk associated with familial hypercholesterolemia: a systematic review of the literature. Clin Ther 2016;38:1696-709.

4. Civeira F, International Panel on Management of Familial Hypercholesterolemia. Guidelines for the diagnosis and management of heterozygous familial hypercholesterolemia. Atherosclerosis 2004;173:55-68.

5. Humphries SE, Cooper JA, Seed M, et al. Coronary heart disease mortality in treated familial hypercholesterolaemia: update of the UK Simon Broome FH register. Atherosclerosis 2018;274:41-6.

6. Mohrschladt MF, Westendorp RGJ, Gevers Leuven JA, et al. Cardiovascular disease and mortality in statin-treated patients with familial hypercholesterolemia. Atherosclerosis 2004;172:329-35.

7. Versmissen J, Oosterveer DM, Yazdanpanah M, et al. Efficacy of statins in familial hypercholesterolaemia: a long term cohort study. BMJ 2008;337.

8. Besseling J, Hovingh GK, Huijgen R, et al. Statins in familial hypercholesterolemia: consequences for coronary artery disease and all-cause mortality. J Am Coll Cardiol 2016;68:252-60.

9. Mundal LJ, Igland J, Veierød MB, et al. Impact of age on excess risk of coronary heart disease in patients with familial hypercholesterolaemia. Heart 2018;104:1600-7.

10. Neil A, Cooper J, Betteridge J, et al. Reductions in all-cause, cancer, and coronary mortality in statin-treated patients with heterozygous familial hypercholesterolaemia: a prospective registry study. Eur Heart J 2008;29:2625-33.

11. Nordestgaard BG, Chapman MJ, Humphries SE, et al. Familial hypercholesterolaemia is underdiagnosed and undertreated in the general population: guidance for clinicians to prevent coronary heart disease: consensus statement of the European atherosclerosis Society. Eur Heart J 2013;34:3478-90.

12. Kerr M, Pears R, Miedzybrodzka Z, et al. Cost effectiveness of cascade testing for familial hypercholesterolaemia, based on data from familial hypercholesterolaemia services in the UK. Eur Heart $J$ 2017;38:1832-9.

13. Louter L, Defesche J, Roeters van Lennep J. Cascade screening for familial hypercholesterolemia: practical consequences. Atheroscler Supp/ 2017;30:77-85.

14. Hartgers ML, Besseling J, Stroes ES, et al. Achieved LDL cholesterol levels in patients with heterozygous familial hypercholesterolemia: A model that explores the efficacy of conventional and novel lipid-lowering therapy. J Clin Lipidol 2018;12:972-80.

15. Pijlman $\mathrm{AH}$, Huijgen R, Verhagen $\mathrm{SN}$, et al. Evaluation of cholesterol lowering treatment of patients with familial hypercholesterolemia: a large cross-sectional study in the Netherlands. Atherosclerosis 2010;209:189-94.

16. Langslet G, Bogsrud MP, Halvorsen I, et al. Long-Term follow-up of young adults with familial hypercholesterolemia after participation in clinical trials during childhood. J Clin Lipidol 2015;9:778-85.

17. Gidding SS, Champagne MA, de Ferranti SD, et al. The agenda for familial hypercholesterolemia: a scientific statement from the American heart association. Circulation 2015;132:2167-92.

18. Hagger MS, Hardcastle SJ, Hingley C, et al. Predicting selfmanagement behaviors in familial hypercholesterolemia using an integrated theoretical model: the impact of beliefs about illnesses and beliefs about behaviors. Int J Behav Med 2016;23:282-94.

19. Hagger MS, Hardcastle SJ, Hu M, et al. Effects of medication, treatment, and behavioral beliefs on intentions to take medication in patients with familial hypercholesterolemia. Atherosclerosis 2018;277:493-501.

20. Green J, Britten N. Qualitative research and evidence based medicine. BMJ 1998;316:1230-2.

21. George M, Freedman TG, Norfleet AL, et al. Qualitative researchenhanced understanding of patients' beliefs: results of focus groups with low-income, urban, African American adults with asthma. $J$ Allergy Clin Immunol 2003;111:967-73.

22. Remien RH, Hirky AE, Johnson MO, et al. Adherence to medication treatment: a qualitative study of facilitators and barriers among a diverse sample of HIV+ men and women in four U.S. cities. AIDS Behav 2003;7:61-72.

23. Hardcastle SJ, Legge E, Laundy CS, et al. Patients' perceptions and experiences of familial hypercholesterolemia, cascade genetic screening and treatment. Int J Behav Med 2015;22:92-100.

24. Frich JC, Malterud K, Fugelli $P$, et al. Experiences of guilt and shame in patients with familial hypercholesterolemia: a qualitative interview study. Patient Educ Couns 2007;69:108-13.

25. Sliwinski SK, Gooding H, de Ferranti S, et al. Transitioning from pediatric to adult health care with familial hypercholesterolemia: listening to young adult and parent voices. J Clin Lipidol 2017:11:147-59.

26. Weiner K, Durrington PN. Patients' understandings and experiences of familial hypercholesterolemia. Community Genet 2008;11:273-82.

27. Finfgeld-Connett D. Generalizability and transferability of metasynthesis research findings. J Adv Nurs 2010;66:246-54.

28. Harris JL, Booth $A$, Cargo $M$, et al. Cochrane qualitative and implementation methods group guidance series-paper 2: methods for question formulation, searching, and protocol development for qualitative evidence synthesis. J Clin Epidemiol 2018;97:39-48.

29. Sheldon TA. Making evidence synthesis more useful for management and policy-making. J Health Serv Res Policy 2005;10(1_suppl):1-5.

30. Ring NA, Ritchie K, Mandava L. A guide to synthesising qualitative research for researchers undertaking health technology assessments and systematic reviews; 2011.

31. Wells M, Williams B, Firnigl D, et al. Supporting 'work-related goals' rather than 'return to work' after cancer? A systematic review and meta-synthesis of 25 qualitative studies. Psychooncology 2013;22:1208-19.

32. Thomas J, Sutcliffe K, Harden A. Children and healthy eating: a systematic review of barriers and facilitators, 2003.

33. Mechta Nielsen T, Frøjk Juhl M, Feldt-Rasmussen B, et al. Adherence to medication in patients with chronic kidney disease: a systematic review of qualitative research. Clin Kidney J 2018;11:513-27.

34. Ma Q, Tso LS, Rich ZC, et al. Barriers and facilitators of interventions for improving antiretroviral therapy adherence: a systematic review of global qualitative evidence. J Int AIDS Soc 2016;19:21166. 
35. Munro SA, Lewin SA, Smith HJ, et al. Patient adherence to tuberculosis treatment: a systematic review of qualitative research. PLoS Med 2007;4:e238.

36. Langlois EV, Tunçalp Özge, Norris SL, et al. Qualitative evidence to improve guidelines and health decision-making. Bull World Health Organ 2018;96:79-79A.

37. Kinnear FJ, Perry R, Searle A, et al. How do the experiences and beliefs of adults and children with heterozygous familial hypercholesterolaemia influence their adherence to treatment? A systematic review of qualitative evidence protocol. Syst Rev 2018;7:120

38. Tong A, Flemming $\mathrm{K}$, Mclnnes $\mathrm{E}$, et al. Enhancing transparency in reporting the synthesis of qualitative research: ENTREQ. BMC Med Res Methodol 2012;12:181.

39. Programme CAS. CASP qualitative research checklist 2017.

40. Thomas J, Harden A. Methods for the thematic synthesis of qualitative research in systematic reviews. BMC Med Res Methodol 2008;8:45

41. Noyes J, Booth A, Flemming K, et al. Cochrane Qualitative and Implementation Methods Group guidance series-paper 3: methods for assessing methodological limitations, data extraction and synthesis, and confidence in synthesized qualitative findings. J Clin Epidemiol 2018;97:49-58.

42. Barnett-Page $\mathrm{E}$, Thomas J. Methods for the synthesis of qualitative research: a critical review. BMC Med Res Methodol 2009;9:59.

43. Carroll C, Booth A. Quality assessment of qualitative evidence for systematic review and synthesis: is it meaningful, and if so, how should it be performed? Res Synth Methods 2015;6:149-54

44. Carroll C, Booth A, Lloyd-Jones M. Should we exclude inadequately reported studies from qualitative systematic reviews? an evaluation of sensitivity analyses in two case study reviews. Qual Health Res 2012;22:1425-34

45. Craig JC, Tong A, Strippoli GFM, et al. A guide to reading and using systematic reviews of qualitative research. Nephrol Dial Transp/ 2014;31:897-903.

46. Frich JC. Living with genetic risk of coronary heart disease: a qualitative interview study of patients with familial hypercholesterolemia, 2007.

47. Urke EB. Young adults with familial hypercholesterolemia and their thoughts on lifelong treatment. A qualitative interview study [Master Thesis], 2016.

48. Weiner K. Patient and professional constructions of familial hypercholesterolaemia and heart disease: testing the limits of the Geneticisation thesis [PhD Thesis], 2006.

49. Agård A, Bolmsjö IA, Hermerén G, et al. Familial hypercholesterolemia: ethical, practical and psychological problems from the perspective of patients. Patient Educ Couns 2005;57:162-7

50. DeAngelis EJ, Mclntosh S, Ahmed CD, et al. Familial hypercholesterolaemia patient-determined themes for communityengaged research. Health Educ J 2018;77:293-302.

51. Hallowell N, Jenkins N, Douglas M, et al. A qualitative study of patients' perceptions of the value of molecular diagnosis for familial hypercholesterolemia (FH). J Community Genet 2017;8:45-52.

52. Jenkins $\mathrm{N}$, Lawton J, Douglas $\mathrm{M}$, et al. Inter-embodiment and the experience of genetic testing for familial hypercholesterolaemia. Sociol Health IIIn 2013;35:529-43.

53. Jenkins $\mathrm{N}$, Lawton J, Douglas $\mathrm{M}$, et al. How do index patients participating in genetic screening programmes for familial hypercholesterolemia (FH) interpret their DNA results? A UK-based qualitative interview study. Patient Educ Couns 2013;90:372-7 https://doi.org/

54. Hollands GJ, Armstrong D, Macfarlane A, et al. Patient accounts of diagnostic testing for familial hypercholesterolaemia: comparing responses to genetic and non-genetic testing methods. BMC Med Genet 2012;13:87-8.

55. Hollman G, Ek A-C, Olsson AG, et al. The meaning of quality of life among patients with familial hypercholesterolemia. J Cardiovasc Nurs 2004;19:243-50.

56. Keenan KF, Finnie RM, Simpson WG, et al. Parents' views of genetic testing and treatment of familial hypercholesterolemia in children: a qualitative study. J Community Genet 2019;10:129-141.

57. Kirkegaard P, Edwards A, Risør MB, et al. Risk of cardiovascular disease? A qualitative study of risk interpretation among patients with high cholesterol. BMC Fam Pract 2013;14:137.

58. Mackie TI, Tse LL, de Ferranti SD, et al. Treatment decision making for adolescents with familial hypercholesterolemia: role of family history and past experiences. J Clin Lipidol 2015;9:583-93.

59. Meulenkamp TM, Tibben A, Mollema ED, et al. Predictive genetic testing for cardiovascular diseases: impact on carrier children. Am J Med Genet A 2008;146A:3136-46.
60. Mortensen GL, Madsen IB, Kruse C, et al. Familial hypercholesterolaemia reduces the quality of life of patients not reaching treatment targets. Dan Med J 2016;63:A5224

61. Senior V, Smith JA, Michie S, et al. Making sense of risk: an interpretative phenomenological analysis of vulnerability to heart disease. J Health Psychol 2002;7:157-68.

62. Frich JC, Ose L, Malterud K, et al. Perceived vulnerability to heart disease in patients with familial hypercholesterolemia: a qualitative interview study. Ann Fam Med 2006;4:198-204.

63. Frich JC, Malterud K, Fugelli P. How do patients at risk portray candidates for coronary heart disease? A qualitative interview study. Scand J Prim Health Care 2007;25:112-6.

64. Weiner K. The tenacity of the coronary candidate: how people with familial hypercholesterolaemia construct raised cholesterol and coronary heart disease. Health 2009;13:407-27.

65. Weiner K. Exploring genetic responsibility for the self, family and kin in the case of hereditary raised cholesterol. Soc Sci Med 2011;72:1760-7.

66. Claassen L, Henneman L, Kindt I, et al. Perceived risk and representations of cardiovascular disease and preventive behaviour in people diagnosed with familial hypercholesterolemia: a cross sectional questionnaire study. J Health Psychol 2010;15:33-43.

67. van Maarle MC, Stouthard MEA, Bonsel GJ. Risk perception of participants in a family-based genetic screening program on familial hypercholesterolemia. Am J Med Genet A 2003;116A:136-43.

68. Claassen L, Henneman L, van der Weijden T, et al. Being at risk for cardiovascular disease: perceptions and preventive behavior in people with and without a known genetic predisposition. Psychol Health Med 2012;17:511-21.

69. Muir LA, George PM, Whitehead L. Using the experiences of people with familial hypercholesterolaemia to help reduce the risk of cardiovascular disease: a qualitative systematic review. J Adv Nurs 2012;68:1920-32.

70. Andersen LK, Jensen HK, Juul S, et al. Patients' attitudes toward detection of heterozygous familial hypercholesterolemia. Arch Intern Med 1997;157:553-60.

71. Tonstad S, Nøvik TS, Vandvik IH. Psychosocial function during treatment for familial hypercholesterolemia. Pediatrics 1996:98:249-55.

72. de Jongh S, Kerckhoffs MC, Grootenhuis MA, et al. Quality of life, anxiety and concerns among statin-treated children with familial hypercholesterolaemia and their parents. Acta Paediatr 2003;92:1096-101.

73. van Maarle MC, Stouthard MEA, Bonsel GJ. Quality of life in a family based genetic cascade screening programme for familial hypercholesterolaemia: a longitudinal study among participants. $J$ Med Genet 2003;40:3e-3.

74. van Maarle MC, Stouthard MEA, Marang-van de Mheen PJ, et al. How disturbing is it to be approached for a genetic cascade screening programme for familial hypercholesterolaemia? psychological impact and screenees' views. Community Genet 2001:4:244-52.

75. Hyttinen L, Kekäläinen P, Vuorio AF, et al. Health-Related quality of life in elderly patients with familial hypercholesterolemia. Int $J$ Technol Assess Health Care 2008;24:228-34.

76. Akioyamen LE, Genest J, Shan SD, et al. Anxiety, depression, and health-related quality of life in heterozygous familial hypercholesterolemia: a systematic review and meta-analysis. $J$ Psychosom Res 2018;109:32-43.

77. Senior V, Marteau TM, Weinman J, et al. Self-Reported adherence to cholesterol-lowering medication in patients with familial hypercholesterolaemia: the role of illness perceptions. Cardiovasc Drugs Ther 2004;18:475-81.

78. Galema-Boers A, Langendonk JG, Roeters Van Lennep J, et al. Developing a prediction model to identify noncompliance in a nurse-led familial hypercholesterolemia clinic. Eur Heart J 2011;1.

79. Galema-Boers JMH, Lenzen MJ, van Domburg RT, et al. Predicting non-adherence in patients with familial hypercholesterolemia. Eur $J$ Clin Pharmacol 2014;70:391-7.

80. Braamskamp MJAM, Kusters DM, Avis HJ, et al. Long-Term statin treatment in children with familial hypercholesterolemia: more insight into tolerability and adherence. Pediatric Drugs 2015;17:159-66.

81. Retterstol K, Mundal L, Igland J, et al. Incidence of various types of atherosclerotic disease in patients with genotyped familial hypercholesterolemia. Atherosclerosis 2017;263:e26.

82. Hopkins PN. Putting into perspective the hazards of untreated familial hypercholesterolemia. J Am Heart Assoc 2017;6. doi:10.1161/JAHA.117.006553

83. deGoma EM, Ahmad ZS, O'Brien EC, et al. Treatment gaps in adults with heterozygous familial hypercholesterolemia in the United 
States: data from the CASCADE-FH registry. Circ Cardiovasc Genet 2016:9:240-9.

84. Saltijeral A, Pérez de Isla L, Alonso R, et al. Attainment of LDL cholesterol treatment goals in children and adolescents with familia hypercholesterolemia. The SAFEHEART follow-up registry. Rev Esp Cardiol

85. Humphries SE, Cooper J, Dale P, et al. The UK paediatric familial hypercholesterolaemia register: Statin-related safety and 1-year growth data. J Clin Lipidol 2018;12:25-32.

86. Galema-Boers AM, Lenzen MJ, Engelkes SR, et al. Cardiovascular risk in patients with familial hypercholesterolemia using optimal lipid-lowering therapy. J Clin Lipidol 2018;12:409-16.

87. Pérez de Isla L, Alonso R, Mata N, et al. Predicting cardiovascular events in familial hypercholesterolemia. Circulation 2017;135:2133-44.

88. Senior V, Marteau T, Weinman J. Perceptions of control over heart disease in people with an inherited predisposition to raised cholesterol. Psychol Health Med 2005;10:16-30.

89. Senior* V, Marteau* TM. Causal attributions for raised cholesterol and perceptions of effective risk-reduction: self-regulation strategies for an increased risk of coronary heart disease. Psychol Health 2007;22:699-717.

90. Tonstad S. Familial hypercholesterolaemia: a pilot study of parents' and children's concerns. Acta Paediatr 1996;85:1307-13.

91. Avis HJ, Kusters DM, Vissers MN, et al. Follow-Up of children diagnosed with familial hypercholesterolemia in a national genetic screening program. J Pediatr 2012;161:99-103.

92. Benson G, Witt DR, VanWormer JJ, et al. Medication adherence, cascade screening, and lifestyle patterns among women with hypercholesterolemia: results from the WomenHeart survey. $J$ Clin Lipidol 2016;10:937-43.

93. Collins R, Reith C, Emberson J, et al. Interpretation of the evidence for the efficacy and safety of statin therapy. The Lancet 2016;388:2532-61.

94. Vuorio A, Kuoppala J, Kovanen PT, et al. Statins for children with familial hypercholesterolemia. Cochrane Database Syst Rev 2017;7.

95. Lozano P, Henrikson NB, Morrison CC, et al. Lipid screening in childhood and adolescence for detection of multifactorial dyslipidemia: evidence report and systematic review for the US preventive services Task force. JAMA 2016;316:634-44.

96. Radaelli G, Sausen G, Cesa CC, et al. Statin treatments and dosages in children with familial hypercholesterolemia: metaanalysis. Arq Bras Cardiol 2018.

97. Hollman G, Olsson AG, Ek A-C. Disease knowledge and adherence to treatment in patients with familial hypercholesterolemia. $J$ Cardiovasc Nurs 2006;21:103-8.

98. Van Maarle MC, Stouthard MEA, Marang-Van De Mheen PJ, et al. Follow up after a family based genetic screening programme for familial hypercholesterolaemia: is screening alone enough? BMJ 2002;324:1367-8.

99. Kinnear FJ, Lithander FE, Hamilton-Shield JP, et al. What dietetic support is available to patients in outpatient lipid clinics in the UK? Atheroscler Suppl 2018;34:e5.

100. Umans-Eckenhausen MAW, Defesche JC, van Dam MJ, et al. Long-Term compliance with lipid-lowering medication after genetic screening for familial hypercholesterolemia. Arch Intern Med 2003;163:65-8.

101. Jones LK, Kulchak Rahm A, Manickam K, et al. Healthcare utilization and patients' perspectives after receiving a positive genetic test for familial hypercholesterolemia. Circ Genom Precis Med 2018;11:e002146.

102. Chisnell J, Marshall T, Hyde C, et al. A content analysis of the representation of statins in the British newsprint media. BMJ Open 2017; $7: \mathrm{e} 012613$.

103. Tonstad S, Sivertsen M. Food dislikes and dietary intake in children with familial hypercholesterolemia and controls. Scandinavian Journal of Nutrition/Naringsforskning 1996;40:146-50.

104. Stender S, Skovby F, Haraldsdóttir J, et al. Cholesterol-Lowering diets may increase the food costs for Danish children. A crosssectional study of food costs for Danish children with and without familial hypercholesterolaemia. Eur J Clin Nutr 1993;47:776-86.

105. Dixon LB, Tershakovec AM, McKenzie J, et al. Diet quality of young children who received nutrition education promoting lower dietary fat. Public Health Nutr 2000;3:411-6.

106. Molven I, Retterstøl K, Andersen LF, et al. Children and young adults with familial hypercholesterolaemia $(\mathrm{FH})$ have healthier food choices particularly with respect to dietary fat sources compared with non-FH children. $J$ Nutr Sci 2013;2:e32.

107. West RJ, FAMILIAL H. Factors influencing drug compliance. Pediatric Research 1980;14:1423.

108. Marteau T, Senior V, Humphries SE, et al. Psychological impact of genetic testing for familial hypercholesterolemia within a previously aware population: a randomized controlled trial. $\mathrm{Am} J \mathrm{~J}$ Med Genet 2004;128A:285-93.

109. Lee S, Akioyamen LE, Aljenedil S, et al. Genetic testing for familial hypercholesterolemia: impact on diagnosis, treatment and cardiovascular risk. Eur J Prev Cardiol 2019 (published Online First: 2019/02/14).

110. Ramli A, Ahmad NS, Paraidathathu T. Medication adherence among hypertensive patients of primary health clinics in Malaysia. Patient preference and adherence 2012;6:613-22.

111. Polonsky W, Henry R. Poor medication adherence in type 2 diabetes: recognizing the scope of the problem and its key contributors. Patient preference and adherence 2016;10:1299-307.

112. Leslie KH, McCowan C, Pell JP. Adherence to cardiovascular medication: a review of systematic reviews. J Public Health 2019;41:e84-94.

113. Sud A, Kline-Rogers EM, Eagle KA, et al. Adherence to medications by patients after acute coronary syndromes. Annals of Pharmacotherapy 2005;39:1792-7.

114. Alm-Roijer C, Stagmo M, Udén G, et al. Better knowledge improves adherence to lifestyle changes and medication in patients with coronary heart disease. Eur J Cardiovasc Nurs 2004;3:321-30.

115. Tiv M, Viel J-F, Mauny F, et al. Medication adherence in type 2 diabetes: the ENTRED study 2007, a French population-based study. PLoS One 2012;7:e32412.

116. Broadbent E, Donkin L, Stroh JC. Illness and treatment perceptions are associated with adherence to medications, diet, and exercise in diabetic patients. Diabetes Care 2011;34:338-40.

117. Pollack MF, Purayidathil FW, Bolge SC, et al. Patient-Reported tolerability issues with oral antidiabetic agents: associations with adherence; treatment satisfaction and health-related quality of life. Diabetes Res Clin Pract 2010;87:204-10.

118. Miller T, DiMatteo R. Importance of family/social support and impact on adherence to diabetic therapy. DMSO 2013;6:421-6.

119. Rintala T-M, Jaatinen P, Paavilainen E, et al. Interrelation between adult persons with diabetes and their family: a systematic review of the literature. J Fam Nurs 2013;19:3-28. 